\title{
COMPARAÇÃO DAS VARIÁVEIS LIMNOLÓGICAS DO RIO TOROPI - RS E DO RIO FORQUETA - RS
}

\author{
Andriele Prunzel Koglin ${ }^{(a)}$, Denise Berwanger ${ }^{\text {(b) }}$ \\ (a) Departamento de Geociências/ Universidade Federal de Santa Maria, andrielekog@ gmail.com \\ (b) Departamento de Geociências/ Universidade Federal de Santa Maria, denise_ziem_ber@hotmail.com
}

\section{EIXO: BACIAS HIDROGRÁFICAS E RECURSOS HÍDRICOS: ANÁLISE, PLANEJAMENTO E GESTÃO}

\section{Resumo}

A água é fundamental para as mais diversas formas de vida em nosso planeta. Assim, a realização do presente trabalho justifica-se visto que o conhecimento das variáveis limnológicas possibilita reverter irregularidades presentes na água. O trabalho objetiva comparar as amostras de água referente ao Rio Toropi - RS e outra ao Rio Forqueta - RS. A metodologia se deu em duas etapas. A primeira consistiu na coleta das amostras e na medição da temperatura in loco. A segunda ocorreu em laboratório, onde foram obtidos dados referentes ao $\mathrm{pH}$, condutividade elétrica e Total de Sólidos em Suspensão (TSS). Como resultado obteve-se uma diferença de condutividade elétrica de $21 \mu \mathrm{S} / \mathrm{cm}-1$ e um TSS quatro vezes maior no Rio Toropi; em contrapartida o Rio Forqueta possui o $\mathrm{pH}$ mais ácido e a temperatura mais elevada. Conclui-se que caso não houvesse a presença da leitaria próximo ao Rio Toropi, os resultados teriam valores mais equilibrados.

Palavras chave: Água, Rio Forqueta, Rio Toropi, Variáveis limnológicas.

\section{Introdução}

A água é fonte da vida. Não importa quem somos, o que fazemos, onde vivemos, nós dependemos dela para viver. A água é provavelmente o único recurso natural que tem a ver com todos os aspectos da civilização humana, desde o desenvolvimento agrícola e industrial aos valores culturais e religiosos arraigados na sociedade. Segundo as estatísticas, $70 \%$ da superfície do planeta é constituída por água. Dessa água toda, de longe o maior volume é água salgada e somente 2,5\% são de água doce e, desses míseros 2,5\%, quase 98\% estão "escondidos" na forma de água subterrânea (BRASIL, 2013)

Devido ao alto potencial hidráulico no Brasil, pode-se observar que cada vez mais a atual sociedade moderna vem se apropriando desse recurso para fins hidroelétricos com objetivo de abastecer a demanda energética da população. Essa apropriação acaba muitas vezes alterando as características da fauna e flora ambiental, principalmente de ambientes aquáticos propiciados pelo barramento e modificação do curso normal da água(TUNDISI apud KAISER, 2015)

Segundo ESTEVES (2011) a avaliação de parâmetros limnológicas "é uma importante ferramenta de estudos direcionados a problemas ambientais em sistemas aquáticos. Sobretudo, o estudo contribui para o 
desenvolvimento de mecanismos que viabilizam a compreensão do funcionamento de ecossistemas fluviais, de modo a favorecer a gestão, monitoramento e recuperação da qualidade da água. A necessidade de monitorar esses ambientes está associada ao gerenciamento dos recursos hídricos exigindo informações a respeito das características da água. Diante desse pressuposto surgem as variáveis limnológicas como representantes das características físicas, químicas, biológicas e geológicas da água."

Desta forma, a realização do presente trabalho justifica-se devido à grande importância de conhecer os dados limnológicos da água dos rios para monitorar e desenvolver mecanismos de amenização do problema apresentado e, por consequência, recuperar a qualidade da água. Esta pesquisa tem como objetivo principal comparar as amostras do Rio Toropi e do Rio Forqueta, considerando as condições de uso da terra no entorno as áreas amostrais.

\section{Metodologia}

\subsection{Desenvolvimento das atividades em campo}

A metodologia desenvolvida se deu em duas etapas. Inicialmente foi feito à coleta das amostras de água em campo, as quais foram coletadas no Rio Toropi, no dia 29 de outubro de 2016 às 18h, e no Rio Forqueta, coletado no dia 11 de dezembro de 2016 às 9h. Nesta etapa inicial foi utilizado garrafas PET de $500 \mathrm{ml}$ e um termômetro para medição da temperatura.

\subsection{Desenvolvimento das atividades em laboratório}

O segundo momento se deu no laboratório da Universidade Federal de Santa Maria - UFSM, onde foram identificadas as seguintes variáveis limnológicas: a condutividade elétrica, o potencial hidrogeniônico (pH) e o total de sólidos em suspensão (TSS).

Para a obtenção do TSS foi conservada a garrafa com a água do rio na geladeira, para depois ser realizada a filtragem. Antes da filtragem, os filtros de celulose, com porosidade de 0,45 um, utilizados passaram por uma secagem inicial de 24 horas em estufa a uma temperatura de $50^{\circ} \mathrm{C}$ para não haver umidade, $\operatorname{logo} \mathrm{em}$ seguida, estes filtros foram pesados para obter o peso inicial (Pi).

Depois disso, foi feita a filtragem onde o filtro foi colocado na base de apoio de um funil preso por prendedor metálico e ajustado à rolha de um frasco de Kitasato, unindo a bomba de vácuo, sendo filtrados $100 \mathrm{ml}$ de cada amostra. Logo após, foi feito o mesmo método de secagem anteriormente citado e passado novamente, tendo assim o peso final (Pf). Para o cálculo do TSS foi utilizada a seguinte expressão:

$$
\mathrm{TSS}=\frac{(\mathrm{Pf}-\mathrm{Pi})}{\mathrm{V}} * 1000
$$


XVII Simpósio Brasileiro

de Geografia Física Aplicada

I Congresso Nacional

de Geografia Física
OS DESAFIOS DA GEOGRAFIA FÍSICA NA FRONTEIRA DO CONHECIMENTO

Instituto de Geociências - Unicamp

Campinas - SP

28 de Junho à 02 de Julho de 2017

Onde: TSS é o Total de Sólidos em Suspensão (mg/L); Pf é o Peso Final (g); Pi é o Peso Inicial (g); V é o Volume filtrado (L).

Por fim, o pH foi medido com o peagâmetro digital e a condutividade elétrica foi medida com o condutivímetro.

\section{Caracterização das áreas de estudo}

O munícipio de Toropi encontra-se localizado na região central do estado, na zona de transição entre a Depressão Periférica e o Planalto Meridional Brasileiro, é banhado pelo Rio Toropi e pelo Rio ToropiMirim distante $360 \mathrm{~km}$ de Porto Alegre. O município de Arroio do Meio é um município do Vale do taquari, rodeado por relevo com grandes elevações, os chamados morros e é irrigado por vários rios e arroios de todos os portes que descem das encostas e da Serra Gaúcha. É banhado pelo Rio Taquari e pelo Rio Forqueta distante $125 \mathrm{~km}$ da capital.

Na figura 1, observa-se a localização dos municípios acima citados.

Figura 1:Mapa de localização do município de Toropi - RS e Arroio do Meio - RS

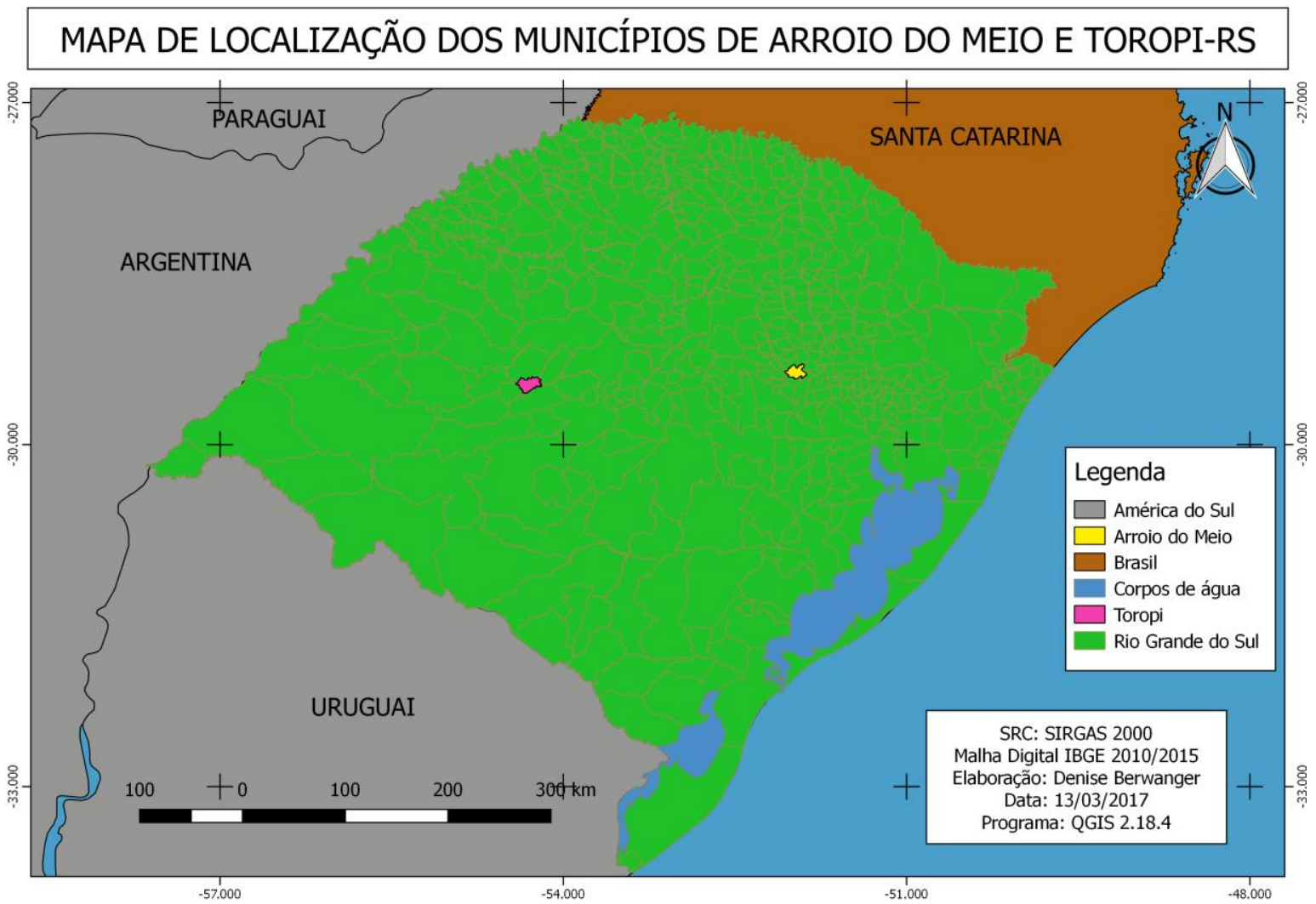

Fonte 1: IBGE, 2010. 


\subsection{Caracterização dos pontos de coleta}

A amostra Rio Toropi foi coletada no dia 29 de outubro às 18 horas. Aproximadamente à 500 metros a montante do ponto de coleta, há despejo de rejeitos provenientes de uma leitaria. Nas proximidades do local de coleta, há pouca vegetação ao redor do rio, cultura de arroz e, por consequência, as chuvas tem erodido as encostas do rio.

A amostra Rio Forqueta foi coletada no dia 11 de dezembro de 2016 às 9 horas. No lado direito do ponto de coleta há a presença de várzea, com o cultivo de milho e soja. Já no lado esquerdo, há uma elevação que dificulta o cultivo em grande escala, nota-se uma maior presença de vegetação com alguns pedaços de terras cultivadas. Em todo percurso do rio, percebe-se a pouca presença de vegetação nas encostas.

\section{Resultados e discussão}

Conforme a tabela 1, a amostra Rio Toropi possui o Total de Sólidos em Suspensão (TSS) igual a 16mg/L, enquanto que a amostra referente ao Rio Forqueta, tem como resultado 4mg/L. Nota-se que o Rio Toropi possui um TSS quatro vezes maior que o Rio Forqueta, o que pode se explicar pela existência de uma leitaria que despeja os rejeitos no leito. Além disso, a cultura do arroz também possui influência, visto que com o bombeamento da água do rio para irrigação da plantação e o intenso desmatamento, provocam erosões e, por consequência, alteração do TSS.

O valor referente a condutividade elétrica da amostra Rio Toropi é de $64 \mu \mathrm{S} / \mathrm{cm}^{-1}$, enquanto que da amostra Rio Forqueta é de $43 \mu \mathrm{S} / \mathrm{cm}^{-1}$. Novamente, percebe-se que o Rio Toropi possui um indicativo de poluentes mais elevado do que o Rio Forqueta, visto que há plantação de arroz, a qual utiliza agrotóxicos, possui os despejos dos rejeitos da leitaria próximo ao local de coleta.

Tabela 1: Resultados referentes da condutividade elétrica e ao $\mathrm{pH}$.

\begin{tabular}{|c|c|c|c|c|}
\hline Variáveis Limnológicas & Total TSS $(\mathrm{mg} / \mathrm{L})$ & $\begin{array}{c}\text { Condutividade } \\
\text { Elétrica }\left(\mu \mathrm{S} / \mathrm{cm}^{-1}\right.\end{array}$ & $\mathrm{pH}$ & Temperatura ${ }^{\circ} \mathrm{C}$ \\
\hline Amostra Rio Toropi & 16 & 64 & 6,7 & 17,6 \\
\hline Amostra Rio Forqueta & 4 & 43 & 5,6 & 25,2 \\
\hline
\end{tabular}

Os resultados apresentados em relação ao pH para a amostra Rio Toropi, foi de 6,7 e para a amostra Rio Forqueta 5,6. De acordo com o Conselho Nacional do Meio Ambiente (CONAMA), na resolução n²0 de 18 de junho de 1986, estabeleceu-se algumas restrições no pH para as quatro classes de águas continentais. Os critérios de proteção à vida aquática, previsto no artigo $4^{\circ}$ das águas salobras, fixam o $\mathrm{pH}$ entre 6 e 9. 
Há também a influência da variável temperatura, onde a amostra Rio Toropi é de $17,6^{\circ} \mathrm{C}$ e a amostra Rio

Forqueta é de $25,2^{\circ} \mathrm{C}$ (diferença de $7,6^{\circ} \mathrm{C}$ ).

\section{Conclusões}

Após a realização desse estudo percebe-se o quanto o uso do solo, o desmatamento, o uso de agrotóxicos e o despejo de rejeitos da leitaria influenciam na qualidade da água, bem como na manutenção da vida aquática.

Conclui-se que caso não houvesse a leitaria despejando rejeitos nas águas do Rio Toropi, provavelmente os resultados das análises teriam valores mais parecidos, visto que ambas as encostas dos rios possuem características em comum como pouca vegetação e intensa utilização do solo para agricultura.

\section{Agradecimentos}

Em especial, gostaríamos de registrar nosso agradecimento ao professor Dr. Waterloo Pereira Filho pela orientação no trabalho e aos acadêmicos Janderlei Dal Osto e Joceli Augusto Gros pelo auxilio na obtenção dos dados em laboratório.

\section{Bibliografia}

BRASIL, Projeto Brasil das águas. A importância das águas. Disponível em:

$<\mathrm{http}$ ://brasildasaguas.com.br/educacional/a-importancia-da-agua/>. Acesso em: 15/12/16.

ESTEVES, F. A. Fundamentos de Limnologia. 3ª ed. Rio de Janeiro: Interciência, 826 p. 2011.

KAISER, Eduardo André. Caracterização de variáveis limnológicas em função do uso da terra e do represamento fluvial. Relatório de estágio (Técnico em geoprocessamento) - Universidade Federal de Santa Maria (UFSM), Santa Maria, 2015.

KONRAD, Carlos Gillberto. Avaliação do Potencial Hidrogeológico do Município de Toropi-RS. Trabalho de Graduação - Universidade Federal de Santa Maria (UFSM), Santa Maria, 2010.

SCHWARTZ, Deni Lineu. RESOLUÇÃO CONAMA No 20. Disponível em:

<http://www.mma.gov.br/port/conama/res/res86/res2086.html)>. Acesso

em: 14/03/2017.

SILVÉRIO DA SILVA, José Luiz. Cadastro dos recursos hídricos subterrâneos do município de Toropi-RS, com sistema de informação geográfica. 2006. XIV Congresso Brasileiro de águas subterrâneas. Disponível em: <https://aguassubterraneas.abas.org/asubterraneas/article/viewFile/22191/14543>. Acesso em: 17/12/16.

STROHSCHOEN, Andreia Aparecida Guimarães. Estrutura da comunidade de macroinvertebrados bentônicos na bacia hidrográfica do rio Forqueta (RS, Brasil) em múltiplas escalas espaciais. Tese de doutorado (Ecologia) - Universidade Federal do Rio Grande do Sul (UFRGS), Porto Alegre, 2011. 